\title{
A Study on the Attitude and Preference of Antenatal Clinic Attendees to Companionship during Labour and Delivery in Alex Ekwueme Federal University Teaching Hospital, Abakaliki
}

\author{
Sunday Uchenna Asogwa, Johnbosco Ifunanya Nwafor* (i), Chuka Nobert Obi, \\ Chukwunenye Chukwu Ibo, Darlington-Peter Chibuzor Ugoji, Ikenna Chidi Ebere, \\ Alfred Nnabugwu Adiele, Ayodele Adegbite Olaleye \\ Department of Obstetrics and Gynaecology, Alex Ekwueme Federal University Teaching Hospital, Abakaliki, Nigeria \\ Email: *nwaforjohnbosco97@gmail.com
}

How to cite this paper: Asogwa, S.U., Nwafor, J.I., Obi, C.N., Ibo, C.C., Ugoji, D.-P.C., Ebere, I.C., Adiele, A.N. and Olaleye, A.A. (2019) A Study on the Attitude and Preference of Antenatal Clinic Attendees to Companionship during Labour and Delivery in Alex Ekwueme Federal University Teaching Hospital, Abakaliki. Advances in Reproductive Sciences, 7, 71-81. https://doi.org/10.4236/arsci.2019.74009

Received: July 27, 2019

Accepted: September 22, 2019

Published: September 25, 2019

Copyright $\odot 2019$ by author(s) and Scientific Research Publishing Inc. This work is licensed under the Creative Commons Attribution International License (CC BY 4.0).

http://creativecommons.org/licenses/by/4.0/

\section{(c) (i) Open Access}

\begin{abstract}
Background: Labour is a stressful physical and psychological experience in a woman's life, requiring optimal coping mechanism. Companionship provides such needed support in this vulnerable moment of women. The presence of a companion of the woman's choice had been noted to have a positive influence on her satisfaction with the birth process. Objectives: To ascertain the attitude of antenatal clinic attendees to companionship in labour and delivery and their preferred companions. Methods: A descriptive cross sectional study was conducted between 10th June 2016 and 28th July 2016 on 297 antenatal clinic attendees at Alex Ekwueme Federal University Teaching Hospital, Abakaliki. The respondents completed an anonymous, self-administered questionnaire assessing the attitude of antenatal clinic attendees to companionship in labour and delivery and their preferred companions. The data was analyzed using Epiinfo ${ }^{\mathrm{TM}}$ version 7.1.5. Results: A total of 297 pregnant women participated in the study. They were mainly Igbos (93.27\%), and Christians (96.97\%). Their ages ranged from 18 - 50 years with most of them between 21 - 30 years $(68.35 \%)$. Most of the women had tertiary education $(48 \%)$, and were unemployed (36.36\%). Ninety two percent of the respondents wished for companionship in labour, while $32.66 \%$ has had companion in previous delivery(ies). All of the women that had experienced companionship expressed satisfaction with it. Majority of them preferred their Partners/Husbands as companions (47\%). Conclusion: Majority of our women were desirous of com-
\end{abstract}


panionship and preferred their partners/husbands.

\section{Keywords}

Attitude, Preference, Antenatal Attendees, Companionship, Labour, Abakaliki

\section{Introduction}

Labour is an intensive, energy-sapping event that mothers undergo in the course of procreation and it is associated with emotional, psychological and physical morbidities and occasionally mortality [1] [2]. The emotional well being of a woman in labour determines the extent of her sense of control [3]-[8]. Sense of control in labour has been found to reduce maternal anxiety during childbirth and ultimately leads to a more positive birth experience [4]-[9].

Health care providers tend to underestimate the importance of the experience of childbirth and focus mainly on its outcomes, such as morbidity and mortality, but even for healthy women giving birth to healthy babies, the experience of childbirth is powerful and long-lasting, with consequences for women's physical and mental health, self-image, and relationship with the baby, partner and family [10]. The presence of a birth companion is clearly linked both to positive birth outcomes and a greater degree of personal control during labour [11]. Evidence indicates that continuous support during labour has a number of measurable positive impacts on key birth outcomes [12]-[19]. It has been found to significantly reduce the number of caesarean sections and operative vaginal deliveries, an increase in the number of normal births, a reduction in the use of analgesia and a reduction in labour duration [18] [19].

With the shift of place of birth from home to the hospital, many practices have changed [3]. In the past, many parturients laboured in the confines of their homes, where they are supported by their mothers or family members [16] [19]. Although in recent years spouses and relatives have been allowed into the labour rooms, a huge number of women still go through labour without the much-needed support [14] [19].

Companionship, by a family member or a doula (a trained labour support person) can include emotional support (continuous presence, reassurance and praise), information about progress in labour, advice regarding coping techniques, comfort measures (such as touch, massage, warm baths/showers, promoting adequate fluid intake and output) and advocacy (helping the woman to articulate her wish and need) [1]-[18].

The most preferred choice of support for most women during delivery is their spouse and as such, majority of women have reported a positive birth experience with the presence of their spouse [12] [17] [19]. Spousal presence during childbirth is also instrumental in relieving the distress associated with uncertainty 
and anxiety faced by parturients when they feel physically and psychologically vulnerable [14] [19].

Women's birth experiences have widespread and long-term implications for women and their families [13] [16]. Poor experience may contribute significantly to perinatal mental health problems including post-traumatic stress disorder and postnatal depression undermine the development of a positive mother-baby attachment and influence women's decisions about future childbearing [18].

In actual clinical practice, there are a wide range of cultural and societal differences in childbirth support system [5] [17]. In developed countries, the main social supporters are usually the partners or close relatives [5] [18]. In contrast, in many developing countries like South America and Africa, companionship during labour is not routine [16] [19].

This study ascertained the opinions of parturients to the presence of a companion during their labour and delivery. It also sought out the preferred companion by the women and the reasons for their choice.

\section{Materials and Method}

Study area: Ebonyi state is one of the five states in the South East Geopolitical zone of Nigeria. It has a population of about 3 million people and is inhabited mainly by the Igbo speaking community. Majority of the population is rural dwellers and farmers. Alex Ekwueme Federal University Teaching Hospital (formerly known as Federal Teaching Hospital), Abakaliki is located within the centre of the state capital. It receives referral from all parts of the state and neighbouring states of Abia, Benue, Cross-River, and Enugu. The antenatal clinic holds daily Mondays through Fridays and is run by consultant Obstetrician and Gynaecologists and resident doctors in the department of Obstetrics and Gynaecology.

Study population: This included all patients attending the antenatal clinic during the study period who give their consents.

Study design: This was a descriptive cross sectional study undertaken between 10th June 2016 and 28th July 2016. Pregnant women irrespective of their gestational age who consented to participate were recruited into the study. Those who withheld their consent were excluded. Data was collected via a self-administered questionnaire in English language (Appendix). A structured and pre-tested questionnaire was prepared first in English and translated to the local language (Igbo), and translated back to English in order to assess its consistency. The first part of the questionnaire included the sociodemographic characteristics of the participants while the second and third parts assessed the attitude and preference of parturient to companionship in labour respectively.

Sample size calculation: The sample size for the study was determined using the prevalence rate of $75 \%$ found in a study by Morhason-Bello et al. [8] in Nigeria. $N=p(1-p) z^{2} / d^{2} . N=$ sample size, $z=$ z-score, $d=$ desired error margin, $p=$ prevalence. Using $95 \%$ confidence interval and prevalence $75 \%, d=$ $0.05, z=1.96, p=0.75 . N=0.75(1-0.75) 1.96^{2} / 0.05^{2}=288$. Sample size $=288+$ 
$20 \%$ attrition $=346$.

Data analysis: The data was analyzed using Epiinfo ${ }^{\mathrm{TM}}$ version 7.1.5 of 2015 CDC Atlanta Georgia USA. Chi-square test was used for proportions. The level of significance was kept at $\leq 0.05$.

Ethical consideration: The ethical approval for the study was obtained from Research and Ethics Committee of Alex Ekwueme Federal University Teaching Hospital, Abakaliki.

\section{Results}

A total of 346 women were interviewed using the questionnaires. Out of these two hundred and ninety seven (297/346) were included in the analysis. The remaining $14.2 \%$ were either not returned or incompletely filled.

Sociodemographic data are shown in Table 1 . Most of the respondents were within the age range of 21 - 30 years, 203 (68.35\%). Two hundred and eighty-eight (96.97\%) were married while 106 (35.69\%) had prior vaginal birth. Two hundred and seventy seven (93.27\%) were Igbos while 285 (95.96\%) were Christians. Two hundred and eighty eight (96.97\%) were booked while the remaining 9 (3.03\%) were on their booking visit. Among the respondents, 108 (36.36\%) were unemployed, 67 (22.5\%) were unskilled, 63 (21.21\%) were skilled and 59 (19.87\%) were professionals.

Figure 1 shows the pie chart of women's response when enquiry was made on their desire for companionship in labour. Majority (92\%) of women expressed their desire for companionship in labour. Only $8 \%$ of the study participants said that they don't need companion in labour.

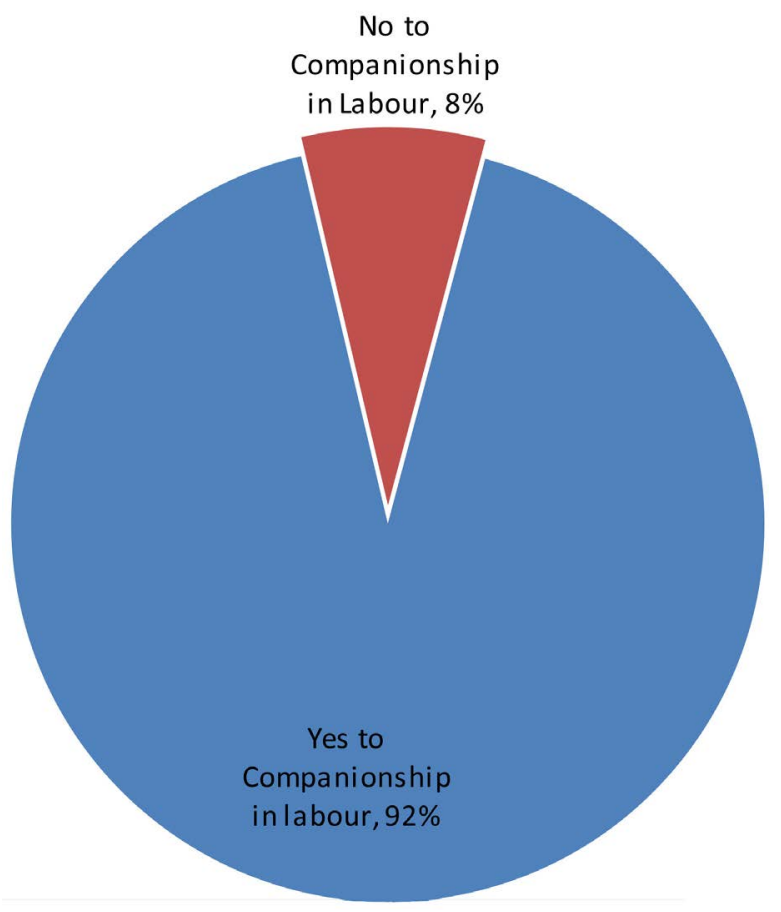

Figure 1. Pie chart showing distribution of attitude to companionship in labour. 
Table 1. Sociodemographic characteristics of the respondents.

\begin{tabular}{|c|c|c|}
\hline Variable & Frequency & Percentage \\
\hline \multicolumn{3}{|l|}{ Age } \\
\hline$<20$ & 18 & 6.06 \\
\hline $21-30$ & 203 & 68.35 \\
\hline $31-40$ & 72 & 24.24 \\
\hline $41-50$ & 4 & 1.35 \\
\hline \multicolumn{3}{|l|}{ Marital status } \\
\hline Single & 5 & 1.68 \\
\hline Married & 288 & 96.97 \\
\hline Divorced & 4 & 1.35 \\
\hline \multicolumn{3}{|l|}{ Education } \\
\hline No formal education & 0 & 0 \\
\hline Primary & 65 & 22 \\
\hline Secondary & 89 & 30 \\
\hline Tertiary & 143 & 48 \\
\hline \multicolumn{3}{|l|}{ Occupation } \\
\hline Unemployed & 108 & 36.36 \\
\hline Unskilled & 67 & 22.56 \\
\hline Skilled & 63 & 21.21 \\
\hline Professional & 59 & 19.87 \\
\hline \multicolumn{3}{|l|}{ Ethicity } \\
\hline Igbo & 277 & 93.27 \\
\hline Others & 14 & 4.71 \\
\hline Hausa/Fulani & 4 & 1.35 \\
\hline Yoruba & 2 & 0.67 \\
\hline \multicolumn{3}{|l|}{ Booking status } \\
\hline Booked & 288 & 96.97 \\
\hline Unbooked & 9 & 3.03 \\
\hline \multicolumn{3}{|l|}{ Parity } \\
\hline 0 & 93 & 31.31 \\
\hline $1-2$ & 69 & 23.23 \\
\hline $3-4$ & 56 & 18.86 \\
\hline$\geq 5$ & 79 & 26.6 \\
\hline
\end{tabular}

Table 2 showed various demographic characteristics of the respondents as it relates to their wish for companionship. Majority of the women within age range of 21 - 30 years (98\%) wished companionship in labour. More married respondents than divorced ones wished for companionship ( $94 \%$ vs $25 \%, p=0.000004$ ). Women who had tertiary education were more desirous of companionship than those with secondary education $(99.3 \%$ vs $87 \%, \mathrm{p}=0.00003)$. There was no 
Table 2. Showed proportion of respondents by their sociodemographic characteristics and their wish for companionship.

\begin{tabular}{|c|c|c|c|}
\hline Demographics & $\mathrm{WC}(\mathrm{n}=273)$ & $\mathrm{WNC}(\mathrm{n}=24)$ & P-Value \\
\hline Age (years) & & & 0.000019 \\
\hline$\leq 20$ & $11(61 \%)$ & $7(39 \%)$ & \\
\hline $21-30$ & 199 (98\%) & $4(2 \%)$ & \\
\hline $31-40$ & $61(85 \%)$ & $11(15 \%)$ & \\
\hline $41-50$ & $2(50 \%)$ & $2(50 \%)$ & \\
\hline Marital status & & & 0.000001 \\
\hline Married & $270(94 \%)$ & $18(6 \%)$ & \\
\hline Divorced & $1(25 \%)$ & $3(75 \%)$ & \\
\hline Single & $2(40 \%)$ & $3(60 \%)$ & \\
\hline Education level & & & 0.00003 \\
\hline Primary & $54(83 \%)$ & $11(17 \%)$ & \\
\hline Secondary & 77 (87\%) & $12(13 \%)$ & \\
\hline Tertiary & $142(99.3 \%)$ & $1(0.7 \%)$ & \\
\hline Occupation & & & 0.086919 \\
\hline Unemployed & $95(87 \%)$ & $13(13 \%)$ & \\
\hline Unskilled & $60(90 \%)$ & $7(10 \%)$ & \\
\hline Skilled & $61(97 \%)$ & $2(3 \%)$ & \\
\hline Professional & 57 (97\%) & $2(3 \%)$ & \\
\hline
\end{tabular}

$\mathrm{n}=$ number of respondents who wished companionship; $\%$ = percentages; $\mathrm{WC}=$ wished companionship; $\mathrm{WNC}=$ wished no companionship.

statistically significant difference in wish for companionship between professionals and the unemployed ( $97 \%$ vs $87 \%, \mathrm{p}=0.061745)$.

Table 3 showed that 273 (92\%) of the respondents wished to have a companion in labour. Sixty eight of the respondents (41.2\%) has had companionship in labour and of them (100\%) were satisfied with their experience. Among the respondents 165 (55.56\%) has had prior vaginal childbirth while 132 (44.44\%) where primigravida or had abdominal delivery in their childbirth.

The pie chart distribution of the type of companion the study participants want is shown in Figure 2. Among women who wanted someone to accompany them during labour, majority 129 (47.25\%) preferred their husbands, 45 (16.48\%) chose their mother, 39 (14.29\%) preferred hospital staffs, 31 (11.36\%) preferred their siblings while the remainder wanted their friend, mother in law, or someone else. When asked reason for support in labour, $89 \%$ of the women cited emotional support (e.g. allay anxiety, provide word of encouragements and boost morale), 6 wanted the companion to run errand (e.g. fetch caregiver and provide necessary materials needed), $3 \%$ chose spiritual support (praying and assuring of God's help) and $2 \%$ desired physical support (e.g. massaging the patient's back). 


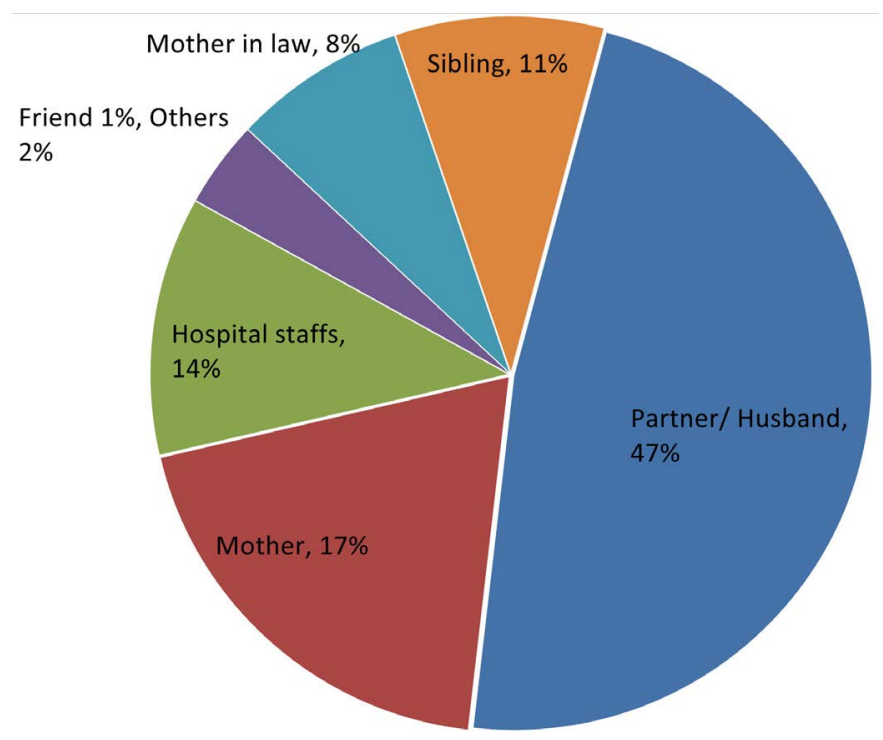

Figure 2. Pie chart showing distribution of preferred companions.

Table 3. Attitude respondents to companionship in labour.

\begin{tabular}{|c|c|c|}
\hline & Frequency & Percentage \\
\hline \multicolumn{3}{|l|}{ Prior vaginal birth } \\
\hline No & 132 & $44.44 \%$ \\
\hline Yes & 165 & $55.56 \%$ \\
\hline \multicolumn{3}{|c|}{ Thinks companionship is necessary in labour } \\
\hline No & 18 & $6.06 \%$ \\
\hline Yes & 273 & $91.92 \%$ \\
\hline Don't know & 6 & $2.02 \%$ \\
\hline \multicolumn{3}{|c|}{ Had companionship in prior childbirth } \\
\hline No & 97 & $58.8 \%$ \\
\hline Yes & 68 & $41.2 \%$ \\
\hline \multicolumn{3}{|c|}{ Satisfaction following companionship } \\
\hline Excellent & 30 & $44.33 \%$ \\
\hline Very good & 32 & $46.39 \%$ \\
\hline Good & 6 & $9.28 \%$ \\
\hline Fair & - & - \\
\hline $\mathrm{Bad}$ & - & - \\
\hline \multicolumn{3}{|c|}{ Wish for companionship in future childbirth } \\
\hline No & 24 & $8 \%$ \\
\hline Yes & 273 & $92 \%$ \\
\hline \multicolumn{3}{|l|}{ Preferred companion } \\
\hline Partner/Husband & 129 & $47 \%$ \\
\hline Mother & 45 & $17 \%$ \\
\hline Hospital staffs & 39 & $14 \%$ \\
\hline Sibling & 31 & $11 \%$ \\
\hline Mother in law & 22 & $8 \%$ \\
\hline Friend & 3 & $1 \%$ \\
\hline Others & 4 & $2 \%$ \\
\hline
\end{tabular}




\section{Discussion}

Although the benefits and subsequently the promotion of support during labour and delivery has been noted in the past, most developing nations such as Nigeria still practice it below expectation [1]. This deprives women of cost effective care in the course of their childbirth [1] [2]. This might be because of cultural background and poor architectural design of labour rooms which discourages companionship.

This study found that the percentage of women who preferred being accompanied during childbirth was high (92\%). About $41.2 \%$ of participants who had prior vaginal birth had some form of companionship in their previous childbirth. This is low when compared with a study in Denmark where $95 \%$ of women in labour had companions [17]. A study done at university college teaching hospital, Ibadan, Nigeria reported that $75 \%$ of the respondents desired companionship in labour [12]. Another study in Saudi Arabia found that 59\% of women had support during labour [18]. Higher prevalence of companionship found in Saudi Arabia and Denmark may be due to socio-cultural differences and better planned health facilities to accommodate companions during labour unlike in our environment were women labour in an open labour room without required privacy.

In index study, most women preferred their husband as labour companion (47.25\%); this however contrasts with study by Bakhata et al. [12] where 68\% of women declined to have male partners present during labour. This difference may be individual or societal perception of the role of male partners. It could also be due to differences in family structures, relationships and ties.

According to the recently updated Cochrane review in July 2013 [19], common elements of companionship during labour include emotional support, information about labour progress and advice regarding coping techniques, comfort measures and advocacy. Similarly, majority of the respondents considered emotional support (89\%) to be the major element.

Significantly more women who received higher education (post secondary), considered companionship is necessary. This might be because of their knowledge of the value. It could also be because they are more cognizant of their rights, and think companions can improve communication with health care professionals in stressful situations such as labour. Although it is not unexpected that those more educated women opted for companionship, enhanced efforts should also be made to propagate the role and value of companionship to those who are less well educated. This is in agreement with other study which demonstrated that educational level of women was an important determinant [12].

Age and marital status was also found to be statistically significant in the wish for companionship. This is in contrast to study by Chiu et al. [5] where age and marital status were not significant factors.

The overall satisfaction rate with the childbirth experience for women that had companionship during labour was relatively good. Their satisfaction were 
graded excellent, in 30 (44.33\%), very good, 32 (46.39\%), and good, 6 (9.28\%). This observation agrees with other studies that noted satisfactory rate as $84.5 \%$ [7].

This study has some limitations. This study is obviously one of few of its kind on the subject matter and an eye opener to the wish of our women. This does not represent the opinion of the entire society. Most of the respondents who had companions in their prior delivery(ies) did so in facilities outside the Teaching Hospital (place of study) because companionship in labour is not commonly practiced in the later. Therefore, a community based study would be preferable.

\section{Conclusion}

In conclusion, companionship in labour is obviously the intense aspiration of parturients in our societies. Their desire to be in the company of their loved ones during one of the most stressful moments of their life should be made a reality. There is still need for further studies on evidence-based benefits of social support to women in labour in our environment. This will provide a substantial fact for advocacy and promotion of the practice.

\section{Conflicts of Interest}

The authors declare no conflicts of interest regarding the publication of this paper.

\section{References}

[1] Sapkota, S., Kobayashi, T., Kakehashi, M., Baral, G. and Yoshida, I. (2012) In the Nepalese Context, Can a Husband's Attendance during Childbirth Help His Wife Feel More in Control of Labour? BMC Pregnancy and Childbirth, 12, 49. https://doi.org/10.1186/1471-2393-12-49

[2] The Royal College of Midwives (2012) Evidence Based Guidelines for Midwifery-Led Care in Labour. Supporting Women in Labour.

[3] Feyer, I.S.S., Monticelli, M., Volkner, C. and Burigo, R.A. (2013) Brazilian Scientific Publications of Obstetrial Nurses on Home Delivery: Systematic Literature Review. Text Context Nursing, Florianopolis, 22, 247-256. https://doi.org/10.1590/S0104-07072013000100030

[4] Emelonye, A.U., Pitkaaho, T. and Vehvilainen-Julklenen, K. (2015) Spousal Presence as a Nonpharmacological Pain Management during Childbirth: A Pilot Study. Nursing Research and Practice, 2015, Article ID: 932763. https://doi.org/10.1155/2015/932763

[5] Chiu, W.K., Chung, W.H., Chan, L.W. and To, W.K. (2015) Companionship during Labour: Attitude and Expectation of Hong Kong Chinese. Hong Kong Journal of Gynaecology, Obstetrics and Midwifery, 15, 124-130.

[6] Vehviläinen-Julkunen, K. and Emelonye, A.U. (2014) Spousal Participation in Labour and Delivery in Nigeria. Annals of Medical and Health Science Research, 4, 511-515. https://doi.org/10.4103/2141-9248.139290

[7] Diniz, C.S.G., Dominingues, R., Torres, J., Dias, M., Schneck, C., Lansky, S., et al. (2014) Implementation of Presence of Companions during Hospital Admission for Childbirth: Data from the Birth I Brazil National Survey. Cadernos de Saúde Pública, Rio de Janeiro, 30, 140-153. https://doi.org/10.1590/0102-311X00127013 
[8] Kungwimba, E., Malata, A., Maluwa, A. and Chirwa, E. (2013) Experience of Women with the Support They Received from Their Birth Companions during Labour and Delivery in Malawi. I Health, 5, 45-52. https://doi.org/10.4236/health.2013.51007

[9] Banda, G., Kafulafula, G., Nyirenda, E., Taulo, F. and Kalilani, L. (2010) Acceptability and Experience of Supportive Companionship during Childbirth in Malawi. BJOG, 117, 937-945. https://doi.org/10.1111/j.1471-0528.2010.02574.x

[10] Hofmeyr, G.J., Nkodem, V.C., Wolman, W., Chalmers, B.E. and Kramer, T. (1991) Companionship to Modify the Clinical Birth Environment: Effects on Progress and Perceptions of Labour, and Breastfeeding. BJOG, 98, 756-764. https://doi.org/10.1111/j.1471-0528.1991.tb13479.x

[11] Alexander, A., Mustafa, A., Emil, S.A., Amekah, E., Engmann, C., Adanu, R., et al. (2013) Social Support during Delivery in Rural Central Ghana: A Mixed Method Study of Women's Preference for and against Inclusion of a Lay Companion in the Delivery Room. Journal of Bio-Science, 46, 669-685.

https://doi.org/10.1017/S0021932013000412

[12] Morhason-Bello, I.O., Olayemi, O., Ojengbede, O.A., Adedokun, B.O., Kuyemi, O.O. and Orji, B. (2008) Attitude and Preferences of Nigerian Antenatal Women to Social Support during Labour. Journal of Bio-Science, 40, 553-562. https://doi.org/10.1017/S0021932007002520

[13] Bakhta, Y. and Lee, R.H. (2010) A Survey of Russian Women Regarding the Presence of a Companion during Labour. International Journal of Gynecology \& Obstetrics, 109, 201-203. https://doi.org/10.1016/j.ijgo.2010.01.021

[14] Oboro, V.O., Oyeniran, A.O., Akinola, S.E. and Isawumi, A.I. (2011) Attitudes of Nigerian Women toward the Presence of Their Husband or Partner as a Support Person during Labour. International Journal of Gynecology \& Obstetrics, 112, 56-58. https://doi.org/10.1016/j.ijgo.2010.07.033

[15] Kabakian-Khasholian, El-Nemer, A. and Bashour, H. (2015) Perceptions about Labour Companionship at Public Teaching Hospitals in Three Arab Countries. International Journal of Gynecology \& Obstetrics, 129, 223-226. https://doi.org/10.1016/j.ijgo.2014.12.005

[16] Maimbolwa, M.C., Sikazwe, N., Yamba, B., Diwan, V.K. and Ransjo-Arvidson (2001) Views on Involving a Social Support Person during Labour in Zambian Maternities. Journal of Midwifery and Women's Health, 46, 226-234. https://doi.org/10.1016/S1526-9523(01)00134-9

[17] Bruggemann, O.M., Parpinelli, M.A., Osis, J.D. and Neto, A.S. (2007) Support to Woman by a Companion of Her Choice during Childbirth: A Randomized Controlled Trial. Reproductive Health, 4, Article No. 5. https://doi.org/10.1186/1742-4755-4-5

[18] Al-Mandeel, H.M., Almufleh, A.S., Al-Damri, A.T., Al-Bassam, Hajr, E.A., Bedaiwi, N.A., et al. (2013) Saudi Women's Acceptance and Attitudes towards Companion Support during Labour: Should We Implement an Antenatal Awareness Program? Annals of Saudi Medicine, 33, 28-33. https://doi.org/10.5144/0256-4947.2013.28

[19] Hodnett, E.D., Gates, S., Hofmeyr, G.F., Sakala, C. and Weston, J. (2011) Continuous Support for Women during Childbirth. Cochrane Database of Systematic Reviews, No. 2, CD003766. https://doi.org/10.1002/14651858.CD003766.pub3 


\section{Appendix}

QUESTIONIARE. To assess the attitude and preference of antenatal clinic attendees to companionship during labour and delivery in Federal Teaching Hospital, Abakaliki.

Instruction: thick $(\sqrt{ })$ in the appropriate boxes.

1) Date

2) Age

$<20 \square, 21-30$

$31-40$

$41-50$ $>50$

3) Marital status

Single $\square$, Married $\square$, Divorced $\square$, Widowed

Married/Separated

4) Parity

5) Religion

Catholic $\square$, Protestant $\square$, Pentecostal $\square$, Muslim $\square$

Traditional $\square$, Others

6) Occupation

Unemployed , Unskilled , Skilled , Professional

7) Ethnic group Ibo $\square$, Hausa/Fulani , Yoruba , Others

8) Level of education Primary $\square$, Secondary $\square$, Tertiary $\square$

9) Husband's occupation Unemployed $\square$, Unskilled $\square$, Skilled $\square$, Professional 10) Booking status Booked $\square$, Unbooked

11) Have you had vaginal delivery before? Yes , No

12) Do you think companionship is necessary in labour? Yes $\square$, No $\square$, Don't know $\square$

13) If No why

14) If yes why

15) Have you had a companion in labour before?

Yes $\square$, No $\square$

16) If yes what was your experience like?

Excellent $\square$, Very good $\square$, good $\square$ , Fair $\square$, Bad

17) If no would you like to have a companion in labour? Yes $\square$, No $\square$

18) Who would you like to be your companion? Partner/Husband $\square$, Mother $\square$, Mother-in-law $\square$, Friend $\square$, Sibling $\square$, Hospital staff $\square$, Others $\square$, Specify 